7-2010

Reversible Luminescent Reaction of Amines with Copper(i)

Cyanide

Amanda N. Ley

Lars E. Dunaway

Timothy P. Brewster

Matthew D. Dembo

et al.

See next page for additional authors

Follow this and additional works at: https://scholarworks.wm.edu/aspubs

Part of the Chemistry Commons 


\section{Authors}

Amanda N. Ley, Lars E. Dunaway, Timothy P. Brewster, Matthew D. Dembo, et al., and Robert D. Pike 


\title{
Reversible Luminescent Reaction of Amines with Copper(I) Cyanide
}

\author{
Amanda N. Ley, ${ }^{a}$ Lars E. Dunaway, ${ }^{a}$ Timothy P. Brewster, ${ }^{a}$ Matthew D. Dembo, ${ }^{a}$ T. David Harris, ${ }^{b}$ \\ François Baril-Robert, ${ }^{c}$ Xiaobo Li, ${ }^{c}$ Howard H. Patterson ${ }^{c}$ and Robert D. Pike ${ }^{* a}$
}

\author{
Received (in $X X X, X X X) X$ th $X X X X X X X X X 200 X$, Accepted Xth $X X X X X X X X X 200 X$ \\ ${ }_{5}$ First published on the web Xth $X X X X X X X X X 200 X$ \\ DOI: $10.1039 / b 000000 x$
}

Copper(I) cyanide exposed to various liquid or vapor-phase amines $(L)$ at ambient temperature produces a variety of visible photoluminescence colors via reversible formation of amine 10 adducts. The adducts show phase matches to authentic $(\mathrm{CuCN}) \mathrm{L}_{n}, n=0.75-2.0$, produced by heating $\mathrm{CuCN}$ with liquid amine.

One of the significant on-going challenges in chemistry is the specific and convenient detection of compounds of interest in 15 the environment. ${ }^{1}$ Detection of volatile organic compounds (VOCs) via chemical "sniffing" requires an interaction between the VOC and a detector substrate, resulting in a measureable change. Crystal inclusion of VOCs into various $\mathrm{d}^{8}$ and $\mathrm{d}^{10}$ metal complexes has been found to affect 20 intermetallic or other weak interactions, yielding visible color changes. $^{2}$ In contrast, direct and reversible VOC-metal bonding is very unusual. ${ }^{3}$ Bonding of various nucleophiles to metal centers can serve to modulate substrate photophysics, leading to a wider variety of responses. Herein we report that 25 reversible surface bonding of amines to $\mathrm{CuCN}$ gives rise to a remarkable range of visible photoluminescent responses.

We have recently reported the structures and luminescence behavior of copper(I) cyanide networks with bridging diamine ligands. ${ }^{4}$ Luminescence emission of $\mathrm{CuCN}$-amine adducts 30 occurs in the visible region, representing a bathochromic shift from the $392 \mathrm{~nm}$ emission of CuCN. A DFT examination of $\left[\mathrm{Cu}_{n}(\mathrm{CN})_{n+1}\right]^{-}$polymeric chains (as models for the infinite chains found in $\mathrm{CuCN}$ ) showed that the favored excitations are of $\pi$-symmetry, corresponding roughly to $\mathrm{d}_{\mathrm{Cu}} / \pi_{\mathrm{CN}} \rightarrow$ $35 \mathrm{pCu} / \pi^{*} \mathrm{CN} .{ }^{5}$ Evidence was found for a low-energy triplet excited state with bent geometry at copper. Since bending at copper is an outcome of ligand coordination, this finding is consistent with the lower energy emission associated with $\mathrm{CuCN}$-amine complexes compared to that of $\mathrm{CuCN}$ itself. ${ }^{4 a}$

40 The observation that $\mathrm{CuCN}$ luminescence wavelength is modulated by various incoming ligands suggests that this system might provide the foundation for an amine vaporsensing device. ${ }^{1}$ We have now found that direct addition of amine (L) liquid or diffusion of amine vapor to solid $\mathrm{CuCN}$ at 45 room temperature produces a variety of visible colored luminescence responses (see Fig. 1, Pipd = piperidine, $\mathrm{Cy}=$ cyclohexyl, Morph $=$ morpholine, Pipz $=$ piperazine, Py $=$ pyridine). While $\mathrm{CuCN}$ produces barely visible luminescence emission centered at $392 \mathrm{~nm},{ }^{4 a} \mathrm{CuCN}$ samples exposed to

50 many liquid or vapor amines luminesce at wavelengths shifted well into the visible region.

To probe the nature of the interaction between $\mathrm{CuCN}$ and

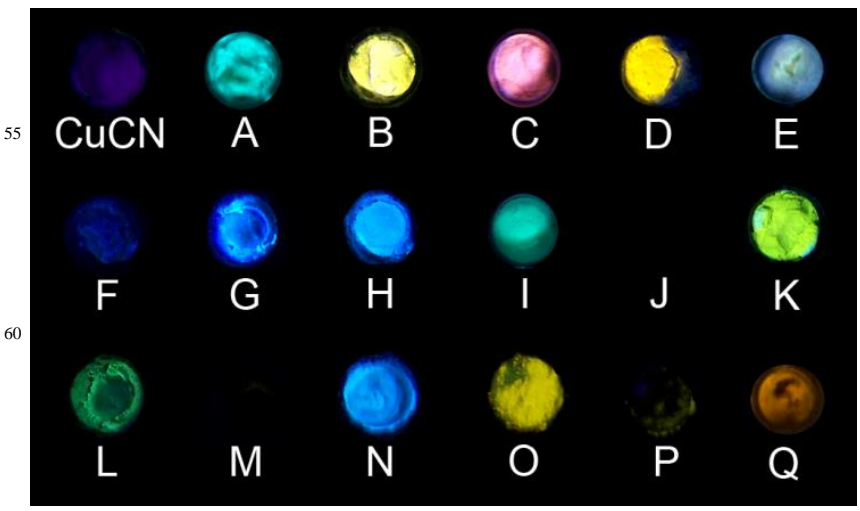

${ }_{55}$ Fig 1. Luminescence of $\mathrm{CuCN}+$ liquid $\mathrm{L}$ under $254 \mathrm{~nm}$ light at room temperature. A: Pipd B: N-MePipd, C: N-Et-Pipd, D: N-MePyrrolidine, E: $\mathrm{Me}_{2} \mathrm{NCy}, \mathrm{F}$ : $\mathrm{NEt}_{3}$, G: N-MeMorph, H: N-MePipz, I: N,N'-Me 2 Pipz, J: Py, K: 2-MePy, L: 3-MePy, M: 4-MePy, N: 2-EtPy, O: 3-EtPy, P: 4-EtPy, Q: ${ }^{-}{ }^{t} \mathrm{BuPy}$.

70

the amines, $\mathrm{CuCN}$ suspensions in various neat amines were heated at $70{ }^{\circ} \mathrm{C} .+$ In most cases the $\mathrm{CuCN}$ did not dissolve in the amine, transforming directly to the solid $(\mathrm{CuCN}) \mathrm{L}_{n}$ complex. Thermogravimetry (TGA) of the $(\mathrm{CuCN}) \mathrm{L}_{n}$ products 75 revealed clean, quantitative loss of amine between 25 and 250 ${ }^{\circ} \mathrm{C}$, depending on amine volatility. The following complexes were prepared: $\mathrm{L}=\mathrm{Py}(n=2, \mathbf{1 a} ; 0.8, \mathbf{1 b}), 2-\mathrm{MePy}(n=1.5$, 2a; 1, 2b), 3-MePy $(n=1.5,3 \mathbf{a} ; 1,3 \mathbf{b}), 4-\mathrm{MePy}(n=1.5,4)$, 2-EtPy $(n=1, \mathbf{5}), 3-\operatorname{EtPy}(n=1.5, \mathbf{6 a} ; 1, \mathbf{6 b}), 4-\operatorname{EtPy}(n=1$, $\left.{ }_{80} 7\right), 4-{ }^{t} \mathrm{BuPy}(n=1.5,8)$, Pipd $(n=1.25,9)$, N-MePipd $(n=1$, 10), N-EtPipd $(n=0.75,11)$, MeMorph $(n=1,12)$, and $\mathrm{Me}_{2} \mathrm{NCy}(n=1, \mathbf{1 3})$. For those amines that yielded more than one product $(\mathbf{1} \mathbf{a} / \mathbf{b}, \mathbf{2} \mathbf{a} / \mathbf{b}, \mathbf{3 a} / \mathbf{b}, \mathbf{6} \mathbf{a} / \mathbf{b})$ the more amine-rich species was produced directly, and overnight vacuum 85 treatment converted it cleanly to the less amine-rich species. These conversions are also evident in the TGA traces (see ESI $\left.^{\dagger}\right)$. Thus in Fig. 2, trace A (2a), reflects the conversion:

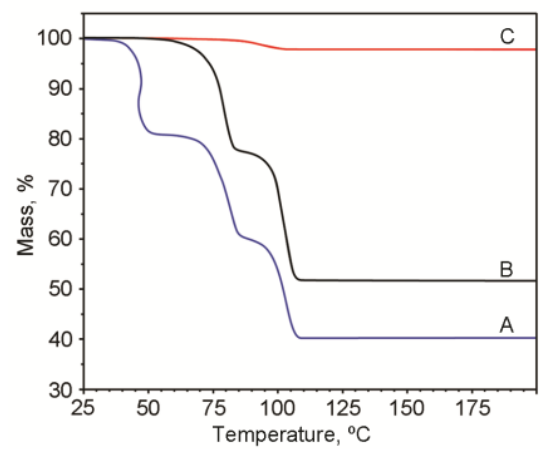

100 Fig 2. TGA traces, A: 2a, B: $\mathbf{2 b}, \mathrm{C}: \mathrm{CuCN}+2-\mathrm{MePy}$ vapor. 
$\mathbf{2 a} \rightarrow \mathbf{2 b} \rightarrow(\mathrm{CuCN})_{2}(2-\mathrm{MePy}) \rightarrow \mathrm{CuCN}$. Trace $\mathrm{B}(\mathbf{2 b})$ shows reactions identical to steps 2 and 3 of trace $A$.

In several cases, X-ray structure determinations were carried out on crystals formed during the neat reactions. All of 5 the new $\mathrm{CuCN}$-amine $\mathrm{X}$-ray structures $(\mathbf{2 b}, \mathbf{6 a}, \mathbf{8}, \mathbf{9}, \mathbf{1 2}$, and 13, see Fig. 3), as well as those already known (1a, 2a, 4, and $(\mathrm{CuCN}) \mathrm{L}, \mathrm{L}=\mathrm{NHEt}_{2}, \mathrm{NEt}_{3}$, quinoline, 3- and 4-acetylPy, and 2,4,6-collidene), ${ }^{6}$ reveal $\mathrm{CuCN}$ chains decorated with $1-2$ amine ligands per $\mathrm{Cu}$ site. In N-MeMorph complex 12, 10 additional long $\mathrm{Cu} \cdots \mathrm{O}(2.537(3) \AA)$ interactions were found, linking the chains into sheets. In the $\mathrm{CuCN}$ chains cyano $\mathrm{C} / \mathrm{N}$ atom positions are disordered in most cases. The cyano- $\mathrm{Cu}-$ cyano angles and $\mathrm{Cu}$-amine bond lengths are relatively large (128.6-154.2 ${ }^{\circ}, 2.04-2.25 \AA$ for 3-coordinate $\mathrm{Cu}$ and 120.7$15139.5^{\circ}, 2.09-2.26 \AA$ for 4-coordinate $\mathrm{Cu}$ ). The latter observations are suggestive of relatively weak $\mathrm{Cu}$-amine bonding. In each $(\mathrm{CuCN}) \mathrm{L}_{n}$ structure, all amine molecules are bonded to copper, with one exception. Complex 8 proved to be $(\mathrm{CuCN})\left(4-{ }^{t} \mathrm{BuPy}\right) \cdot 1 / 2\left(4-{ }^{t} \mathrm{BuPy}\right)$, having a half molecule of 20 free $4^{t} \mathrm{BuPy}$ in the asymmetric unit. Powder diffraction patterns for neat-reaction bulk products 1a, 2a, 4, 8, 9, 12, and 13 showed good agreement to those calculated from the corresponding X-ray structures (see $\mathrm{ESI}^{\dagger}$ ), while those of $\mathbf{2 b}$ and $6 \mathbf{a}$ did not, possibly reflecting polymorphism.

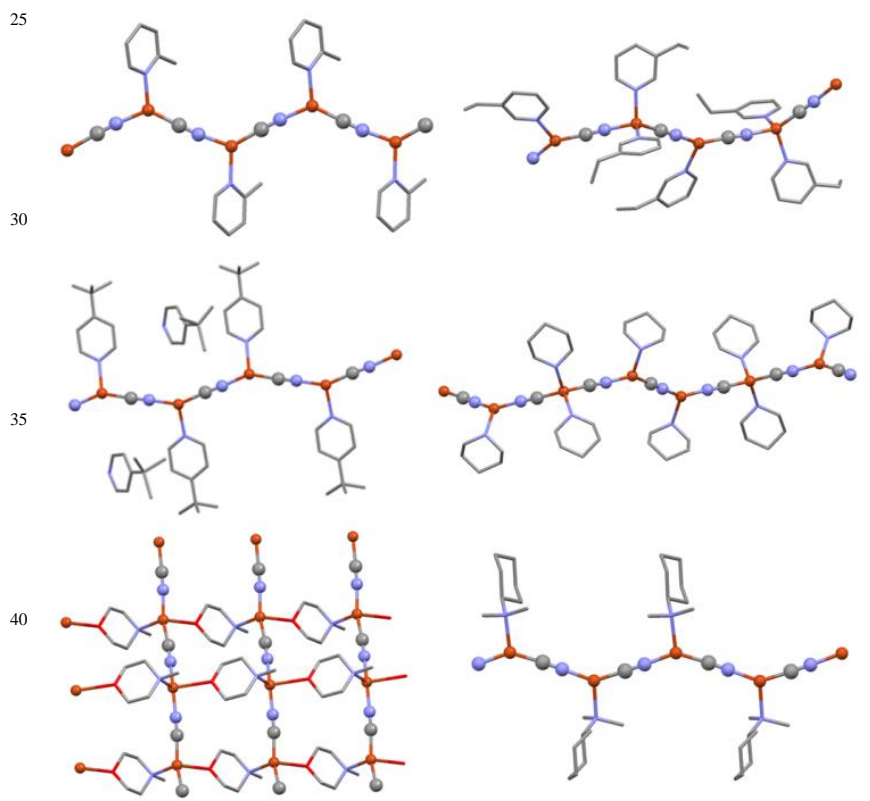

Fig 3. X-ray structures of $\mathbf{2 b}, \mathbf{6 a}, \mathbf{8}, \mathbf{9}, \mathbf{1 2}$, and 13. Copper and cyano atoms shown as spheres. Amine ligands shown as wireframe. Orange $=\mathrm{Cu}$, grey $=\mathrm{C}$, blue $=\mathrm{N}$, red $=\mathrm{O}$. Hydrogen atoms omitted.

50

Importantly, the luminescence behavior of these authentic $(\mathrm{CuCN}) \mathrm{L}_{n}$ samples was found to be analogous in color to that observed in amine-exposed $\mathrm{CuCN}$ (see Fig. 1 above and S1, $\mathrm{ESI}^{\dagger}$ ). X-ray powder patterns were collected for samples of ${ }_{55} \mathrm{CuCN}$ that were exposed to amine vapor or liquid at ambient temperature. Fig. 4 shows the resulting patterns for $\mathrm{CuCN}$ exposed to Py vapor (A), $\mathrm{CuCN}(\mathrm{B})$, and $(\mathrm{CuCN})_{5} \mathrm{Py}_{4}(\mathbf{1 b}, \mathrm{C})$. It can readily be seen that $\mathrm{CuCN}$ exposed to Py shows traces

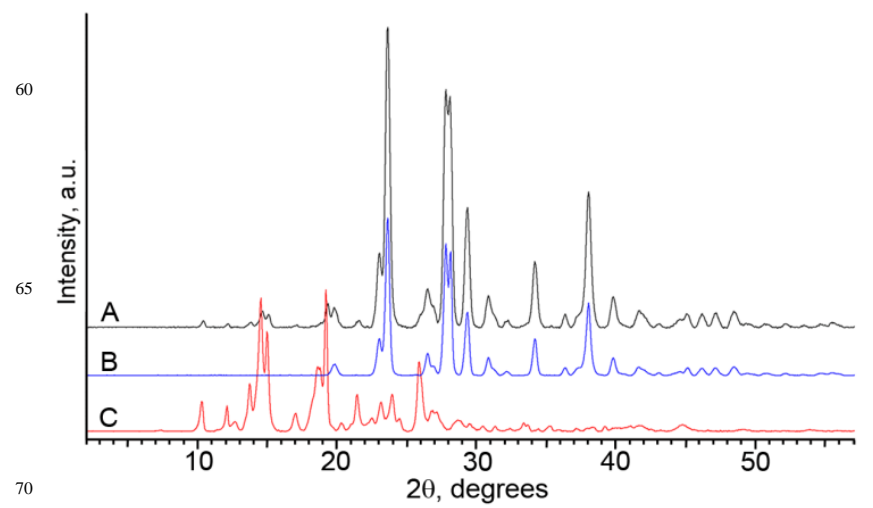

Fig 4. X-ray powder traces, $\mathrm{A}: \mathrm{CuCN}+\mathrm{Py}$ vapor, $\mathrm{B}: \mathrm{CuCN}$, C: $\mathbf{1 b}$.

of the $\mathbf{1 b}$ phase, while remaining mostly $\mathrm{CuCN}$. Under these 75 mild conditions, it seems reasonable to infer that $\mathbf{1 b}$ is formed through partial surface reaction of amine with the $\mathrm{CuCN}$ particles whose bulk remains unaffected. TGA further reveals that the amine-exposed $\mathrm{CuCN}$ samples indeed lose amine at the same temperature as do the authentic $(\mathrm{CuCN}) \mathrm{L}_{n}$ 80 compounds. Thus, as illustrated in Fig. 2 above, while $(\mathrm{CuCN}) \mathrm{L}_{n}$ samples show volatilization of $40-60 \%$ of their mass ( $\mathrm{A}$ and $\mathrm{B}$ ), the amine-exposed samples lose less than $3 \%$ (C). Finally, it is noteworthy that the liquid- or vapor-exposed samples quickly lose their visible luminescence when placed 85 under vacuum, in stark contrast to the authentic $(\mathrm{CuCN}) \mathrm{L}_{n}$ compounds which only partially lose amine over a period of weeks under vacuum (although 1a, 2a, 3a and 6a transform over a few hours to $\mathbf{1 b}, \mathbf{2 b}, \mathbf{3 b}$ and $\mathbf{6 b}$, see above). The overall behavior of the $\mathrm{CuCN}$-amine system is summarized in Scheme 901 . The top pathway describes the essentially irreversible formation of authentic $(\mathrm{CuCN}) \mathrm{L}_{n}$ via the reaction of $\mathrm{CuCN}$ in neat heated amine. The bottom pathway traces the reversible surface formation of $\mathrm{CuCN}$-amine adducts through ambient temperature exposure of $\mathrm{CuCN}$ to amine liquid or vapor.

95

100 105

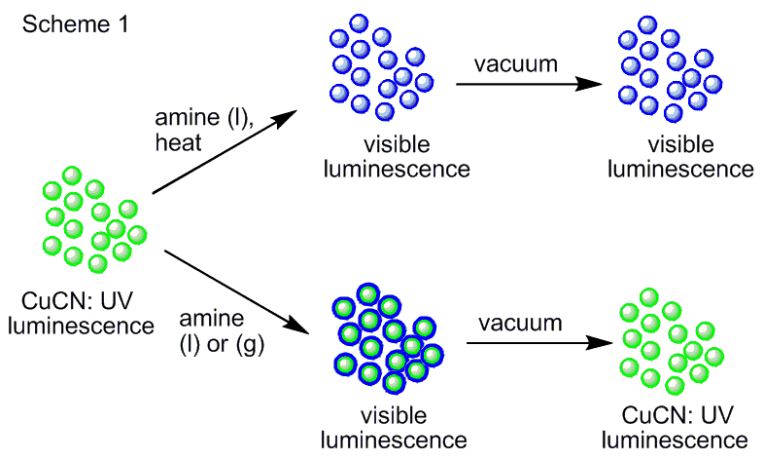

The aromatic amine complexes of $\mathrm{CuCN}$ luminesce upon either long $(365 \mathrm{~nm})$ or short $(254 \mathrm{~nm})$ wavelength excitation, 110 while the aliphatic amine adducts luminesce only upon short wavelength excitation. Initial studies of $(\mathrm{CuCN}) \mathrm{L}_{n}$ photophysics reveal high energy (HE) blue emission, often accompanied by a less intense low energy (LE) band. For example, two $\mathrm{CuCN}$ complexes have been found with 2115 MePy: yellow-emitting 2a and blue-emitting 2b (Note that evidence of both the yellow and blue emission is evident in 
Fig. 1K.) In Fig. 5 the $77 \mathrm{~K}$ emission spectra of $2 \mathbf{a}$ show both HE and LE bands, but $\mathbf{2 b}$ exhibits only a HE band. Preliminary studies show emission lifetimes in the microsecond range and quantum yields in the range of 0.5 .

5 Importantly, with regard to the luminescence sensor potential of $\mathrm{CuCN}$ for amines, we note the diverse emission colors for the $\mathrm{CuCN}$-adducts of chemically similar amines: compare e.g. Pipd (Fig. 1A, blue-green), N-MePipd (Fig. 1B, yellow), and N-EtPipd (Fig. 1C, pink) or Py (Fig. 1J, dark), 2-MePy (Fig. ${ }_{10} 1 \mathrm{~K}$, blue/yellow), 3-MePy (Fig. 1L, green), 4-MePy (Fig. 1M, dark), 2-EtPy (Fig. 1N, blue), 3-EtPy (Fig. 1O, yellow), 4EtPy (Fig. 1P, dark), and $4-{ }^{t}$ BuPy (Fig. 1Q, orange).

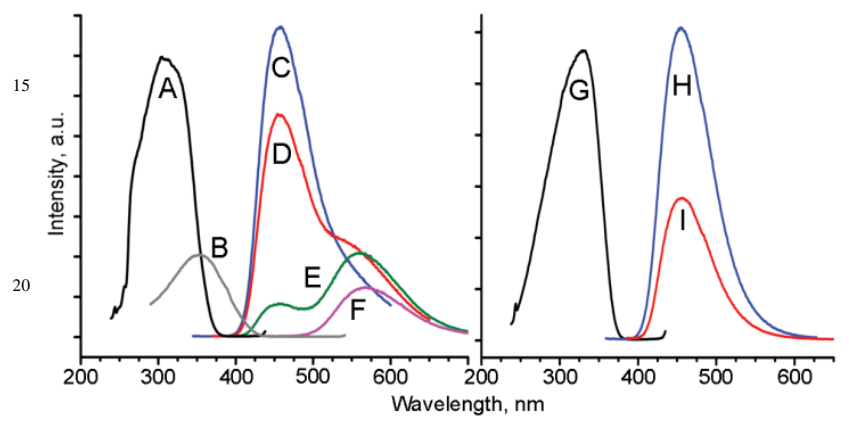

Fig 5. Luminescence spectra $(77 \mathrm{~K})$ of $\mathbf{2 a}$, A-B: excitation ${ }_{25}$ (emission $\lambda=458,561 \mathrm{~nm}$, respectively), C-F: emission (excitation $\lambda=315,340,365,420 \mathrm{~nm}$, respectively) and $\mathbf{2 b}$, G: excitation (emission $\lambda=452 \mathrm{~nm}$ ), $\mathrm{H}-\mathrm{I}$ : emission (excitation $\lambda=329,356 \mathrm{~nm}$, respectively).

30 In conclusion, we report unique and remarkable liganddependent luminescence behavior upon the fully-reversible reaction of a number of amines with $\mathrm{CuCN}$. The ligandinduced $\mathrm{CuCN}$ emission shift from the UV into the visible region offers the potential for a sniffing detection system for 35 amines or other nucleophilic VOCs. Emission color differences resulting from very similar amines are noted in some cases, offering the potential for independent monitoring of multiple chemically related analytes.

We gratefully acknowledge the National Science ${ }_{40}$ Foundation (CHE-0848109, RDP), (CHE-0351877, HHP), (CHE-0443345, X-ray equipment), the Petroleum Research Fund (RDP, 44891-B3), the Howard Hughes Medical Institute. We thank Prof. Jeffrey R. Long (Univ. Calif. Berkeley) for generously allowing use of facilities.

\section{${ }_{45}$ Notes and references}

${ }^{a}$ Department of Chemistry, College of William and Mary, Williamsburg, VA 23187-8795. Fax: (757)221-2715; Tel: (757)221-2555; E-mail: rdpike@wm.edu

${ }^{b}$ Department of Chemistry, University of California, Berkeley, CA 94720 501460

${ }^{c}$ Department of Chemistry, University of Maine, Orono, ME 04469-5706 $\uparrow$ Electronic Supplementary Information (ESI) available: [(1) synthetic details, yields, and analyses (2) crystal structure determination tables. (3) TGA traces for all $(\mathrm{CuCN}) \mathrm{L}_{n}$ compounds, (4) experimental and calculated $55 \mathrm{X}$-ray powder patterns for all $(\mathrm{CuCN}) \mathrm{L}_{n}$. (5) X-ray Powder Patterns for $\mathrm{CuCN}+\mathrm{L}$ experiments. (6) luminescence photograph and spectra for authentic $(\mathrm{CuCN}) \mathrm{L}_{n}$.]. See DOI: XX.XXXX/XXXXXXX

$\$$ Representative Synthesis: 1a. Copper(I) cyanide $(0.150 \mathrm{~g}, 1.67 \mathrm{mmol})$ was suspended in about $5 \mathrm{~mL}$ Py in a sealed tube under Ar. The mixture
60 was heated to $70{ }^{\circ} \mathrm{C}$ in an oil bath overnight without stirring. After cooling, the suspended solid was collected by means of filtration, washed with diethyl ether, and then air dried for $15 \mathrm{~min}$. A yellow powder was isolated (0.393 g, $1.59 \mathrm{mmol}, 94.7 \%)$. See ESI for additional synthesis and analytical data. General Method for Vapor Diffusion Reactions. 80 $65 \mathrm{mg} \mathrm{CuCN}$ powder or pressed pellet (prepared using an IR press) in a 10 $\mathrm{mL}$ beaker was placed in a small jar containing about 1-2 $\mathrm{mL}$ of liquid amine. After a few min. the CuCN luminescence reflected formation of the surface $\mathrm{CuCN}$-amine phase.

$\S$ Crystal Data: All crystals from neat reactions, data collection: $\mathrm{T}=$ $70100(2) \mathrm{K}$ (except 8), $\lambda=1.54178 \AA ̊ ̊ .2$ b: $\mathrm{C}_{7} \mathrm{H}_{7} \mathrm{CuN}_{2}, \quad M 182.69$, monoclinic, $P 2_{1} / \mathrm{c}, \quad a 10.0593(2), \quad b \quad 8.7276(1), \quad c \quad 8.9901(2) \AA, \quad \beta$ $108.709(1)^{\circ}, \mathrm{V} 747.57(2) \AA^{3}, Z 4,7274$ refl., 1273 independ., $\mathrm{R}_{\text {int }}=$ $0.0362, \mathrm{R} 1=0.0276(I>2 \sigma(\mathrm{I})), \mathrm{w} R 2=0.0791$ (all data), CCDC 743728 . 6a: $\mathrm{C}_{23} \mathrm{H}_{27} \mathrm{Cu}_{2} \mathrm{~N}_{5}, M$ 500.58, orthorhombic, $P 2_{1} 2_{1} 2_{1}, a 8.6557(2), b$

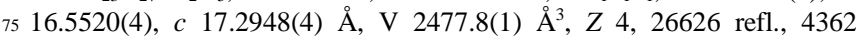
independ., $\mathrm{R}_{\text {int }}=0.0362, \mathrm{R} 1=0.0217(I>2 \sigma(\mathrm{I})), \mathrm{w} R 2=0.0574$ (all data), Flack $=0.00(2), \quad \mathrm{CCDC}$ 743729. 8: $\mathrm{C}_{29} \mathrm{H}_{39} \mathrm{Cu}_{2} \mathrm{~N}_{5}, \quad M$ 584.73, orthorhombic, Fdd2, a 14.9500(2), b 35.3082(4), c 11.6471(1) $\AA$, V 6148.0(1) $\AA^{3}, Z 8, \mathrm{~T}=296(2) \mathrm{K}, 16270$ refl., 2594 independ., $\mathrm{R}_{\text {int }}=$ $800.0307, \mathrm{R} 1=0.0311(I>2 \sigma(\mathrm{I})), \mathrm{w} R 2=0.0934($ all data $)$, Flack $=0.02(5)$, CCDC 743727. 9: $\mathrm{C}_{23} \mathrm{H}_{44} \mathrm{Cu}_{3} \mathrm{~N}_{7}, M$ 609.27, monoclinic, $C 2 / \mathrm{c}, \quad a$ 26.3331(2), b 5.2292(1), c 23.7064(2) $\AA, \beta$ 122.6785(3) ${ }^{\circ}, \mathrm{V} 2747.68(6)$ $\AA^{3}, Z$ 4, 14544 refl., 2413 independ., $\mathrm{R}_{\text {int }}=0.0294, \mathrm{R} 1=0.0212(I>$ $2 \sigma(\mathrm{I})), \mathrm{w} R 2=0.0594$ (all data), $\mathrm{CCDC}$ 743724. 12: $\mathrm{C}_{6} \mathrm{H}_{11} \mathrm{CuN}_{2} \mathrm{O}, M$ 85 190.71, orthorhombic, Ama2, a 9.7119(2), b 12.2714(3), c 6.2836(2) Å, V 748.87(3) $\AA^{3}, Z$ 4, 3902 refl., 661 independ., $\mathrm{R}_{\text {int }}=0.0379, \mathrm{R} 1=0.0175$ (I $>2 \sigma(\mathrm{I})), \mathrm{w} R 2=0.0406$ (all data), Flack $=0.03(4)$, CCDC 743726. 13: $\mathrm{C}_{9} \mathrm{H}_{17} \mathrm{CuN}_{2}, M$ 216.79, orthorhombic, $P 2_{1} 2_{1} 2_{1}, a$ 6.3145(1), $b$ 9.3450(1), $c$ $17.4458(3) \AA, \mathrm{V} 1029.46(3) \AA^{3}, Z 4,10747$ refl., 1814 independ., $\mathrm{R}_{\text {int }}=$ $900.0285, \mathrm{R} 1=0.0164(I>2 \sigma(\mathrm{I})), \mathrm{w} R 2=0.0440$ (all data), Flack $=0.53(2)$, CCDC 743725. For crystallographic data in CIF or other electronic format, see DOI: XX.XXXX/XXXXXXX Programs: Bruker SMART Apex II and SAINT+ control and integration software, ${ }^{7}$ Bruker SHELXTL and WinGX for structure refinement and graphics. ${ }^{8}$

1 (a) D. James, S. M. Scott, Z. Ali, W. T. O'Hare, Microchim. Acta 2005, 149, 1. (b) M. Ando, Trends Anal. Chem. 2006, 25, 937.

2 (a) E. Cariati, X. Bu, P. C. Ford, Chem. Mater. 2000, 12, 3385. (b) W. Lu, M. C. W. Chan, N. Zhu, C.-M. Che, Z. He, K.-Y. Wong, Chem. Eur. J. 2003, 9, 6155. (c) P. Du, J. Schneider, W. W. Brennessel, R. Eisenberg, Inorg. Chem. 2008, 47, 69. (c) M. L. Muro, C. A. Daws, F. N. Castellano, Chem. Commun. 2008, 6134. (d) K. A. McGhee, K. R. Mann, J. Am. Chem. Soc. 2009, 131, 1896. (e) J. Ni, L.-Y. Zhang, H.-M. Wen, Z.-N. Chen, Chem. Commun. 2009, 3801.

105 (f) J. Ni, Y.-H. Wu, X. Zhang, B. Li, L.-Y. Zhang, Z.-N. Chen Inorg. Chem. 2009, 48, 10202.

3 (a) M. Albrecht, M. Lutz, A. L. Spek, G. van Koten, Nature 2000, 406, 970. (b) J. Lefebvre, R. J. Batchelor, D. B. Leznoff, J. Am. Chem. Soc. 2004, 126, 16117. (c) E. J. Fernández, J. M. Lopez-de110 Luzuriaga, M. Monge, E. Olmos, R. C. Puelles, A. Laguna, A. A. Mohamed, J. P. Fackler, Jr., Inorg. Chem. 2008, 47, 8069.

4 (a) M. J. Lim, C. A. Murray, T. A. Tronic, K. E. deKrafft, A. N. Ley, J. C. deButts, R. D. Pike, H. Lu, H. H. Patterson, Inorg. Chem. 2008, 47, 6931. (b) T. A. Tronic, K. E. deKrafft, M. J. Lim, A. N. Ley, R. 115 D. Pike, Inorg. Chem. 2007, 46, 8897. (c) R. D. Pike, K. E. deKrafft, A. N. Ley, T. A. Tronic, Chem. Commun. 2007, 3732.

5 C. A. Bayse, T. P. Brewster, R. D. Pike, Inorg. Chem. 2009, 48, 174.

6 (a) J. C. Dyason, P. C. Healy, L. M. Engelhardt, C. Pakawatchai, V. A. Patrick, A. H. White, J. Chem. Soc., Dalton Trans. 1985, 839. (b) M. M. Olmstead, G. Speier, L. Szabó, Acta Crystallogr., Sect. C 1993, 49, 370. (c) G. A. Bowmaker, K. C. Lim, B. W. Skelton, A. H. White, Z. Naturforsch. 2004, 59b, 1264. (d) S. E. H. Etiaw, S. A. Amer, M. M. El-bendary, Polyhedron 2009, 28, 2385. (e) S. E. H. Etiaw, S. A. Amer, M. M. El-bendary, J. Mater. Sci. 2010, 45, 1307.

1257 (a) SMART Apex II, Data Collection Software, version 2.1; Bruker AXS Inc.: Madison, WI, 2005; (b) SAINT Plus, Data Reduction Software, version 7.34a; Bruker AXS Inc.: Madison, WI, 2005.

8 (a) G. M. Sheldrick, SHELXTL PC, version 6.12; Bruker AXS Inc.: Madison, WI, 2005. (b) L. J. Ferrugia, WinGX, version 1.70.01, J. Appl. Cryst., 1999, 32, 837. 